This is an electronic reprint of the original article. This reprint may differ from the original in pagination and typographic detail.

Author(s): Karoly, Adrienn

Title: $\quad$ Feedback on individual academic presentations: exploring Finnish university students' experiences and preferences

Year: $\quad 2015$

Version:

Please cite the original version:

Karoly, A. (2015). Feedback on individual academic presentations: exploring Finnish university students' experiences and preferences. In J. Jalkanen, E. Jokinen, \& P. Taalas (Eds.), Voices of pedagogical development : expanding, enhancing and exploring higher education language learning (pp. 105-130). Research-publishing.net. https://doi.org/10.14705/rpnet.2015.000289

All material supplied via JYX is protected by copyright and other intellectual property rights, and duplication or sale of all or part of any of the repository collections is not permitted, except that material may be duplicated by you for your research use or educational purposes in electronic or print form. You must obtain permission for any other use. Electronic or print copies may not be offered, whether for sale or otherwise to anyone who is not an authorised user. 


\title{
Feedback on individual academic presentations: exploring Finnish university students' experiences and preferences
}

\author{
Adrienn Károly ${ }^{1}$
}

\section{Abstract}

$\mathrm{W}$

ith an increasing emphasis on measuring the outcomes of learning in higher education, assessment is gaining an ever more prominent role in curriculum design and development as well as in instructional practices. In formative assessment, feedback is regarded as a powerful pedagogical tool driving student engagement and deep learning. The efficacy of feedback, however, depends on a multitude of factors. From a learning cultures perspective (James 2014), assessment strives for an appropriate balance between structural constraints and individual agency. To have a better grasp of how feedback functions in practice, it is useful to investigate students' views and preferences as well as the immediate and wider contexts shaping these constructs. The small-scale research reported in this article explores Finnish university students' prior experiences and initial preconceptions regarding feedback on individual academic presentations with a view to enhancing feedback practices.

Keywords: feedback, higher education language learning, academic expertise, student attitudes and beliefs.

\footnotetext{
1. Language Centre, University of Jyväskylä, Finland; adrienn.karoly@jyu.fi

How to cite this chapter: Károly, A. (2015). Feedback on individual academic presentations: exploring Finnish university students' experiences and preferences. In J. Jalkanen, E. Jokinen, \& P. Taalas (Eds), Voices of pedagogical development Expanding, enhancing and exploring higher education language learning (pp. 105-130). Dublin: Research-publishing.net. doi:10.14705/rpnet.2015.000289
} 


\section{Introduction}

Higher education is facing a number of challenges worldwide, from changing industry demands and increasing calls for accountability and quality to continuously expanding and diversifying student populations and constraints on funding as well as resources. These trends influence not only the positions and interests of various stakeholders but also the educational experience. Some researchers have voiced deep concerns about the negative consequences of these tendencies, which lead to growing pressures and tensions (Gibbs 2006; Hussey \& Smith 2002). For example, due to the intensifying competition, economic interests and market pressures often dominate over educational and professional considerations at multiple levels of decision-making (Amsler \& Bolsmann 2012; Chapleo 2005). Others have called for more comprehensive research on the linguistic corollaries of globalisation and internationalisation, particularly as they relate to the spread of English as the language of instruction in non-native contexts (Marginson \& van der Wende 2007).

Assessment, often regarded as a central component of teaching and learning (Ashford-Rowe, Herrington \& Brown 2014; Boud \& Falchikov 2006; Clark 2012; Sambell, McDowell \& Montgomery 2013; Wiliam 2011), has been gaining increased research attention in the context of higher education, where the effects of the above-mentioned factors are most directly felt. Assessment practices are influenced not only by dominant educational philosophies but also by supranational policy actors. Since the launch of the European Higher Education Area (EHEA) in 2010, the EU has placed special emphasis on improving the quality of teaching and learning with a view to enhancing mobility and employability. Even though the education policy remains the prerogative of the Member States, EU policies play an important role in informing institutional decision-making.

In the Standards and Guidelines for Quality Assurance in the EHEA (ESG), developed in 2005 and promoted through an EU recommendation, assessment is seen as instrumental in enhancing student learning and evaluating the effectiveness of teaching (ENQA 2009). The ESG represents a milestone in 
European higher education policy because it emphasises cooperation and at the same time acknowledges the diversity and autonomy of higher education institutions (Stensaker, Harvey, Huisman, Langfeldt \& Westerheijden 2010). On the other hand, it also signals a growing focus on normative conceptions of good practices in higher education. Capturing this tension, the learning cultures approach to assessment (James 2014) suggests that assessment is a complex social practice, shaped by the dialectic relationship between structure and agency. James (2014) argues that in order to enhance assessment practices, it is important to reflect on social interests and influences (including their wider cultural dimensions) and investigate students' and teachers' collective and individual beliefs and views.

The small-scale, localised empirical research reported in this article was conducted within an ongoing project aiming to improve feedback practices at the Language Centre of the University of Jyväskylä. It explores a group of Finnish university students' prior experiences along with their views and preferences regarding feedback related to individual presentations on compulsory academic English courses. Since there can be substantial differences between students in terms of prior experiences and views, exploring these can provide valuable information for teachers. Furthermore, tailoring assessment to the students' individual beliefs and expectations can make students more engaged with their learning. Motivated by these aims, the study addresses the following research questions:

- How much experience do students have making individual oral presentations at the start of the first compulsory academic English course?

- What kind of previous experiences do students have regarding feedback in the case of individual oral presentations?

- What are the students' specific views and expectations concerning various types of feedback related to the preparation and delivery of individual oral presentations? 


\section{The concepts of assessment for learning and feedback landscape}

Assessment has two main types depending on its primary purpose. Summative assessment measures student achievement at the end of the instructional process by comparing it against some standard. A certain level of performance is required for progression or certification, but grades can also serve quality assurance purposes. On the other hand, formative assessment aims to enhance student learning and motivation through continuous feedback (e.g. Gardner, Harlen, Hayward \& Stobart 2010; Sambell et al. 2013; Wiliam 2011).

Formative assessment helps students to develop into self-regulated learners, so it guides learning in the long term (cf. sustainable assessment, Boud 2000, and authentic assessment, Sambell et al. 2013). The terms feed-forward and feedup also imply a process-based, formative conceptualisation of assessment, viewing feedback as a means to enhance future learning in educational and workplace contexts (Hounsell, McCune, Hounsell \& Litjens 2008). Besides supporting student learning, formative assessment provides valuable information for the teacher about the effectiveness of the instructional process (Bloxham \& Boyd 2008).

While the term assessment of learning refers solely to summative assessment, assessment for learning includes both summative and formative elements, and is based on the idea that all forms of assessment should contribute to student learning. Therefore, it can be considered a holistic model of assessment. According to Sambell et al. (2013: 6-7), it is underpinned by six principles: (1) using authentic and complex assessment tasks, (2) relying on both summative and formative assessment, (3) providing opportunities for practice through a wide range of low-stakes activities, which help to increase students' competence and build their confidence before high-stakes summative assessment takes place, (4) offering different forms of formal feedback from multiple sources, (5) providing opportunities for diverse forms of informal feedback from various sources, and (6) developing students' self-regulatory capacities, which help them become effective lifelong learners. 
In contemporary educational research, feedback is regarded as a key dimension of assessment for learning (Biggs \& Tang 2011; Hattie \& Timperley 2007), and researchers underline its contextual and socially constructed nature (Boud \& Falchikov 2006; Evans 2013; James 2014; Wiliam 2011). Evans's (2013) notion of the feedback landscape implies that although theoretical principles of effective feedback designs can be identified, their implementation in a given context is not always simple. The way individuals experience and respond to feedback depends on an array of personal and contextual variables. In an attempt to illustrate the complexity of feedback exchanges between students and teacher, Evans (2013: 98) lists the following twelve key factors discussed in the literature: (1) ability/intelligence/levels of understanding of academic content and process, (2) personality, (3) gender, (4) culture/ethnicity, (5) social and cultural capital, (6) previous experiences of learning and schema, (7) attributions/motivation/ self-efficacy/resilience, (8) perceived relevance of the task/support, (9) ability to navigate the learning communities and filter relevant information, (10) beliefs about learning and expectations of the learning environment, (11) cognitive styles/approaches to learning, and (12) perceived role(s) within the academic learning communities. Evans (2013) mentions three additional mediators affecting teacher feedback: (13) awareness of other contexts students are working in, (14) alignment with other modules, and (15) knowledge of students and level of adaptation/affordances. Teacher feedback is in the centre, but the author also emphasises the role of alternative sources of feedback.

Unfortunately, teachers typically work under tight constraints of time and resources, and the rationale behind using peer feedback is often simply to shift some of the burden of assessment onto the students to ease heavy teacher workloads (Evans 2013). Another problem can be a mismatch between student and teacher beliefs about the essential role of feedback. Nevertheless, if designed and implemented in an interactive, timely, and integrated manner, feedback can be highly motivational. By using objective and easily accessible criteria, applying clear principles, providing desirable models and guidance, and training students in giving and receiving feedback, teachers can greatly enhance student learning. Ideally, the learning objectives are closely aligned not only with instructional but also with assessment methods (Topping 2010). 
With regard to self-assessment, which is an important component of selfregulation, Evans (2013) emphasises that its efficacy also depends on several factors. She suggests moving from subjective self-assessment/self-reflection practices to self-directed assessment utilising external feedback, which can lead to a more objective assessment of one's own abilities. Evans (2013) also stresses that the development of self-assessment skills is a continuous process, requiring instructional scaffolding as well as consideration of the differences in students' abilities and dispositions. While most contemporary research underlines the crucial role of collaboration in promoting self-regulatory capacities, Evans (2013) notes that for more introverted students, tasks based on independent work might be more natural and productive. As Cain (2012) has pointed out, the ideal of the extraverted personality prevails in contemporary education and working life, while introversion is generally associated with shyness and ineffectiveness, and is often considered inferior or even pathological. The importance of group work and collaboration is undeniable, but through the exclusive or uncritical use of such activities (which are more suited for extroverted students), teachers may hinder autonomy and independent thought and unwittingly promote group thinking and conformity. Since using certain types of feedback - such as public group peer feedback or face-to-face teacher feedback - might not be suitable for everyone, teachers should provide options for students based on their individual preferences.

\section{Research design}

\subsection{Setting and participants}

The research was conducted at the University of Jyväskylä in the fall semester of the 2014-15 academic year. A questionnaire was sent to 115 students enrolled in the first compulsory English course (Academic Reading or Academic Reading and Communication Skills), of whom 40 returned it (representing a $34.7 \%$ response rate), 6 males and 34 females. Their age ranged from 19 to 31 years $(M=23.1, S D=3.15)$. The students were studying at the following faculties (number of students in brackets): social sciences (16), humanities (11), natural 
sciences (12), and sports and health sciences (1), majoring in psychology (2), sociology (7), social work (4), philosophy (2), social and public policy (1), history (1), ethnology (1), speech communication (1), Swedish (2), literature (2), Finnish (3), art history (1), environmental science and technology (3), physics (4), accounting (2), mathematics (3), and sport medicine (1). They have spent from 1 to 13 years in higher education $(M=2.9$, mode $=2)$.

\subsection{Data collection and analysis}

An online questionnaire was used to collect data. This instrument was chosen over interviews because it enabled the collection of both quantitative and qualitative data from a larger group of participants, it ensured anonymity to the respondents, and it was easier to administer with students studying at different departments. Initially two language versions of the questionnaire were developed, and the first version of the English language questionnaire was piloted during the spring semester with 37 students. The original questions were refined or modified after identifying ambiguities and the range of possible answers. The final version of the questionnaire was sent by e-mail to students registered for the compulsory academic English courses offered in the 2014 autumn semester. Participation in the research was voluntary.

The first four questions elicited background information from the participants (gender, age, number of years spent in higher education, and main subject). The main part of the questionnaire comprised 27 items, including both closed and open-ended questions. Some of the questions were contingency questions, limited to a subset of respondents based on their answers to an earlier filter question. The questionnaire consisted of two sections: the first one (Questions 1-9) focused on students' previous feedback experiences related to individual oral presentations during their university studies, while the second part addressed their views and preferences concerning various types of feedback related to individual presentations. Numerical data were analysed by descriptive statistical methods (calculating frequency distributions and central tendencies), and a thematic analysis was conducted on the qualitative data obtained from the open-ended questions. In the coding, a data-driven perspective was adopted 
(Boyatzis 1998), whereby data was first categorised into major themes (based on recurring patterns emerging from the responses), which formed the basis of the subsequent analysis.

\section{Results and discussion}

\subsection{Students' previous feedback experiences}

The first question was related to students' prior experiences preparing and delivering an individual academic presentation. Twenty-eight respondents (70\%) reported having had experience making such presentations, primarily in courses related to their main subject and/or in other compulsory language courses. $30 \%$ of the respondents, however, had no prior experience, suggesting that the individual presentation was a less frequently used activity in some departments during the first and second year, while group presentations seemed to be common.

The results indicating that students started the compulsory English course with varying degrees of experience has important implications for teachers. According to the literature, previous experiences strongly influence motivation, self-efficacy (confidence in one's ability) and resilience (ability to cope with stress) as well as the perceived difficulty of the task (Evans 2013). Students who are inexperienced in making individual presentations will probably require more guidance in the preparation stage and more feedback from multiple sources following the final presentation. It should also be noted that although some students have experience making group presentations, preparing and delivering an individual presentation requires additional competences and different strategies.

Questions 2 and 3 were targeted only at those students who reported having had experience making individual presentations $(n=28)$. They told who they had received feedback from in the preparation stage and after the final performance. The respondents marked the types of feedback they had received (see Figure 1). 
Figure 1. Frequency of receiving feedback from different sources before and after the individual presentation

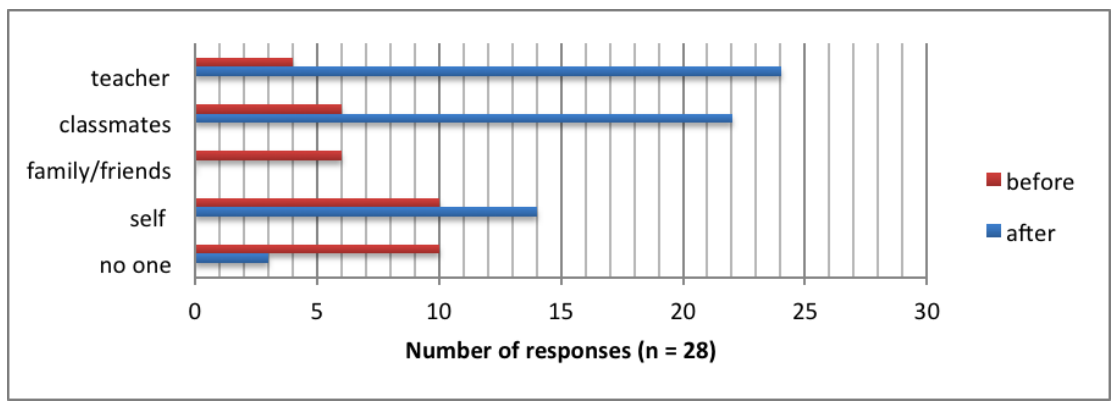

In the preparation stage, feedback seemed to be less common although ten respondents reported having received feedback from peers and family members/ friends respectively. Feedback appeared to be more typical after the presentation, particularly from the teacher (24 students) and peers (22 students), although half of the respondents had also had to reflect on or analyse their own performance. Interestingly, four respondents indicated that they had not received any feedback after delivering the presentation.

Questions 4 and 5 focused more closely on teacher feedback that students received after the presentation. The respondents $(n=28)$ first had to select the forms of feedback they had received from a pre-given list. Feedback was divided into six main types along the following three dimensions: degree of specificity (general vs. more detailed), medium (oral vs. written) and mode (public/open vs. private/individual). Based on the responses, it seems that oral feedback was the most typical from the teacher. General oral feedback given in front of the others appears to be the most frequent (13 students), but oral feedback (both general and more detailed) given face-to-face was also common (marked by ten and nine students respectively). Written teacher feedback seemed to be less typical. Only four students had received general written feedback individually, and only three got more detailed, individual feedback. Teachers' preference for oral feedback might be related to the fact that giving written feedback is more time-consuming. On the other hand, some teachers 
may perceive oral feedback as more effective due to its interactive nature. Still, as Evans (2013) points out, using a generic 'best-practice' strategy is not always a good idea as some students may find detailed written feedback more useful (as will be shown later in this research as well). Finally, four students reported that they had not received any feedback from the teacher after their presentation. This finding is rather unexpected as researchers emphasise the key role of teacher feedback in student learning.

In Question 6, respondents who received feedback from the teacher after the presentation $(n=24)$ specified what aspects of the presentation were mentioned in the feedback. Teacher comments were mostly related to structure (mentioned by ten students), language (including grammar, vocabulary, and pronunciation; eight students), nonverbal communication (including the use of voice; eight students), topic (eight students), argumentation/reasoning/ criticality (five students), slides (four students), professional background knowledge (two students), and cohesion (one student). Interestingly, argumentation, which is related to critical thinking and is supposed to be a key feature of academic presentations, was only rarely mentioned in the teacher feedback.

The next question focused on students' previous experiences regarding peer feedback after the individual presentation. Students $(n=28)$ selected the forms of feedback they had received on a pre-given list (note: students could mark more than one option). Based on their responses, it seems that teachers used different peer feedback practices. Among those who got feedback from the others, the most common type of feedback was general oral feedback in class (eight students), followed by general written feedback from everyone (seven respondents), more detailed oral feedback in class (five students), and more detailed written feedback from everyone (four students). Interestingly, eight students reported having received no peer feedback at all.

The next two questions were concerned with self-analysis as a type of feedback. In response to the question whether the respondents had to reflect on or analyse their own performance after the individual presentation, 12 students gave a 
positive answer, while 16 students indicated that they were not required to do this task $(n=28)$. The following question was targeted only at those students who had to analyse themselves $(n=12)$, and aimed to find out whether the self-analysis was based on a video recording of the presentation. Half of these respondents (six students) indicated that their presentations had been video recorded.

Finally, the last question in this section was related to the task of students grading their own performance $(n=28)$. Only five students reported that they had had to do this after the individual presentation, indicating that self-grading was not a common task. Indeed, self-grading is a rather controversial issue, with some researchers emphasising the risk of grade inflation. This means that students tend to give higher grades to themselves, particularly in high-stakes situations (Andrade \& Valtcheva 2009). Other researchers, however, argue that if designed and implemented appropriately, self-grading can increase student motivation, responsibility, ownership, and the level of engagement with the assessment criteria, and can help students to improve their ability to judge their own achievement or performance more objectively (Kearney 2013; Strong, Davis \& Hawks 2004).

Overall, the results of the first part of the survey indicate that students arrived at the compulsory classes with different feedback experiences, which could have strongly influenced the way they valued, interpreted and responded to various forms and sources of feedback. Sambell et al. (2013) have argued that addressing these diverse needs and preferences can significantly increase student engagement. Students more fully grasp the relevance of different activities and become more aware of the links between courses that often appear to be isolated and unrelated with repetitive activities and assignments. In Evans's (2013) feedback landscape model, the academic learning community includes the immediate academic community (programme of study) as well as wider social (personal and professional) communities. By building on students' previous experiences of feedback exchanges within this complex network, teachers can make students more aware of the continuity and recursive nature of the learning process as well as their own learning progress. 


\subsection{Students' views and preferences regarding feedback}

The second section of the questionnaire focused on students'views and preferences regarding various types of feedback related to individual presentations. The first question aimed to explore students' perceptions about the main purpose of feedback $(n=40)$. The analysis of the responses revealed four main functions for feedback. The first one implies a technical approach and is related to the role of feedback in the development of certain skills (in the case of oral presentations primarily communication and presentation skills). 31 students emphasised this function of feedback. The second general theme emerging from the responses has a psychological orientation. 11 students highlighted the role of feedback in increasing personality traits such as self-confidence and self-esteem. Nine respondents placed the main emphasis on how feedback helped them understand themselves better, as well as see themselves and the world from a different perspective. Finally, two students underlined the importance of feedback as a form of interaction between individuals. According to them, feedback can serve as a useful vehicle for assessing the effects of communication and checking whether the audience has understood the message the way it was intended. Interestingly, two students seemed to be unsure about the main purpose of feedback, which may be linked to previous negative experiences, originating from a lack of clarity and guidance or the methods used by the teacher.

In the next two questions, the respondents had to rate the importance of different types of feedback on a 4-point scale (ranging from very important to not important at all) in the case of feedback from the teacher, peers, self and family members/friends. Figure 2 and Figure 3 summarise students' preferences before and after the presentation, respectively.

In the preparation stage, the majority of the respondents seemed to attach high importance to self-reflection, with $37.5 \%$ rating it as very important, and $50 \%$ as important. With regard to peer feedback, $65 \%$ of the students found it very important or important, while $35 \%$ considered it less important. In comparing the responses with those given to the next question, it seems that peer feedback was generally regarded as much more important after the final performance, 
with $40 \%$ rating it as very important and $60 \%$ as important. Interestingly, almost $60 \%$ of the respondents liked receiving feedback from relatives or friends while preparing for the presentation.

Figure 2. Frequency distribution of students' views on the importance of receiving feedback from different sources before the presentation $(n=40)$

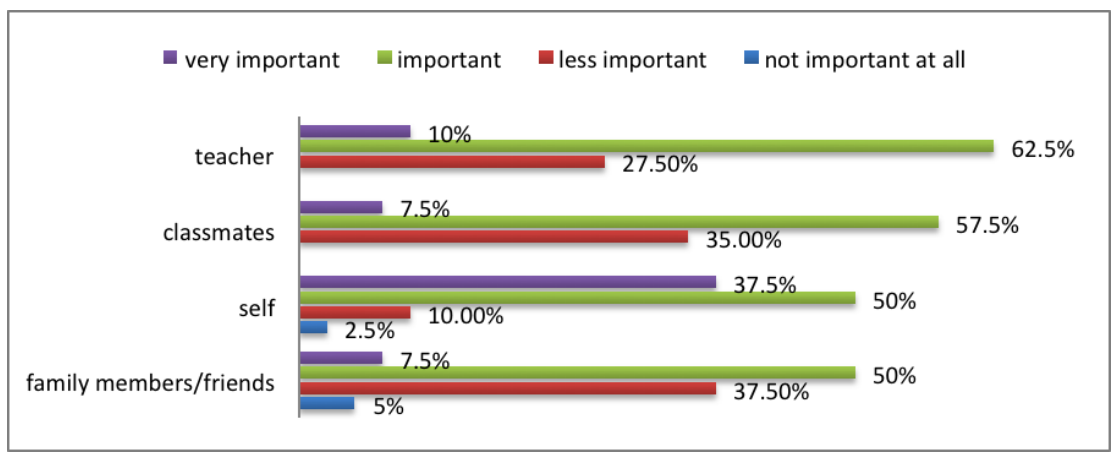

Figure 3. Frequency distribution of students' views on the importance of receiving feedback from different sources after the presentation $(n=40)$

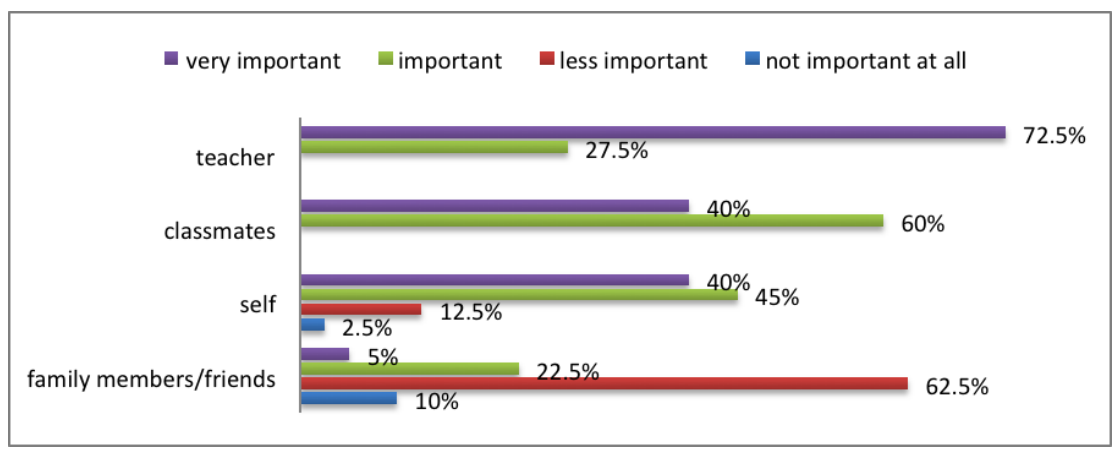

These people did not necessarily have the competence to judge the overall quality of the presentation, but they could easily comment on such aspects as the clarity 
of the main message, non-verbal communication, interaction, and the design of the slides. Relying on friends and family members as sources of feedback can also help students to overcome their nervousness, particularly if peer feedback is not used before the presentation. Concerning feedback after the presentation, $75 \%$ of the respondents attached the highest importance to receiving feedback from the teacher although peer feedback and self-reflection were also seen as very important or important. Students' preference for teacher feedback is somewhat natural although Evans (2013) underlines that for some students, the teacher may not be the most valued source of feedback. Other authors emphasise that trust plays an essential role in teacher-student relationships, which can easily be undermined if 'transmissive-style rituals' dominate teachers' instructional practices, denying the social and iterative nature of feedback (Boud \& Molloy 2013). Finally, assessment practices that rely too much on teacher feedback do not reflect real-life settings, so students often regard them as inauthentic and thus demotivating (Sambell et al. 2013). Therefore, students need to realise that since people have different beliefs, values and preferences, in real life different individuals can judge the same performance or interpret the same message differently.

The next item in the questionnaire was an open-ended question, which focused on students' preferences regarding teacher feedback when preparing the presentation. More specifically, it aimed to explore what aspects of the presentation the respondents would like to receive comments on from the teacher. The most common theme emerging from the responses was the structure of the presentation, with 16 students mentioning it. Within this group, three students mentioned that they would prefer to get feedback on how to start the presentation in an effective and interactive way. Nine students reported that they would like to receive feedback on the topic of the presentation beforehand. Other common themes mentioned were related to content (seven students), clarity of focus (four students), planning the length of the presentation (four students) and grammar (three students). Six students, however, indicated that comments from the teacher in the preparation stage were not necessary. One respondent emphasised that he or she prefers working autonomously, while another student stressed the importance of learning from his or her own mistakes. The others 
seemed to be more concerned with the time and effort that this type of feedback requires from the teacher. The responses suggest that feedback in the preparation stage could work most effectively if it remains optional. It is also clear from the responses that even if the general principles of making a good presentation are covered in class, some students require practical help related to the particular presentation they are working on.

The next question was concerned with teacher feedback after the final presentation. On a pre-given list, the respondents $(n=40)$ rated the importance of receiving teacher feedback regarding various aspects of the presentation. The list contained 22 specific aspects related to structure, content, language, and the delivery of the presentation, each of which had to be rated on a 4-point scale (ranging from very important to not important at all). The responses indicate that students generally considered all these aspects important to some extent, so the response 'not important at all' was extremely rare. The aspects related to structure and content were generally seen as very important or important, while students' attitudes were more mixed regarding the aspects related to language and delivery, with the responses being more evenly distributed across the categories. Students seem to be particularly divided on some of the language-related aspects. For example, pronunciation was seen as very important by seven, important by 16 , and less important by 17 students, while grammar was considered to be very important by three, important by 19 , less important by 17 students, and not important at all by one student. With regard to general/academic and fieldspecific vocabulary, the number of students who rated them as very important or important was higher than in the case of pronunciation and grammar although these numbers were still lower than for structure and content-related aspects. The aspect that was considered very important or important by the highest number of students was the overall structure of the presentation (39 students altogether), while comments on the design of the slides were viewed as less important or not important at all by the highest number of the respondents ( 27 students). These findings seem to confirm arguments that assessment should focus primarily on essential generic and transferable skills, such as critical thinking, innovation, or creativity (Kearney 2013) rather than on technical competence or language, particularly in the case of individual academic presentations. 
With regard to students' views on the most useful forms of teacher feedback after the presentation $(n=40)$, the responses indicate a marked preference for detailed feedback given individually - either orally or in writing ( $40 \%$ and $30 \%$ respectively) - although general written individual feedback was also marked by six students $(15 \%)$. At the same time, fewer respondents seemed to like general oral feedback. The most common justification for favouring written feedback was that it is possible to re-read it, reflect on it at leisure, and use it as a point of reference in the future. Students who favoured individual feedback emphasised that they found it more personal. According to some respondents, individual feedback is more effective if given face-to-face as they have the opportunity to ask questions and react to the teacher's comments immediately, making communication more interactive and authentic. Those respondents who preferred general oral feedback given publicly (in front of the others) emphasised that this enables other students to learn from the discussion, regardless of the actual quality of the performance.

The next question was concerned with teacher feedback during the delivery of the presentation. Almost all respondents $(n=40)$ expressed a dislike for any kind of comments during the presentation except for technical issues and problems related to voice and tempo of speech. A few students further pointed out that nonverbal cues (an encouraging smile or gesture) or some motivating words could be helpful for those students who are overly nervous.

Regarding numerical teacher assessment, the responses were rather mixed. Students' views were explored through two questions, one using a 5-point Likert scale $(1=$ not useful...5 = very useful $)$, followed by an open-ended question asking for justification. Out of the 40 respondents, 14 (35\%) had a neutral opinion, rating the usefulness of grades in the middle of the scale, six students (15\%) marked it as less useful, and 12 students (30\%) as somewhat useful. On the two extremes, five students (12.5\%) regarded grades as not useful at all, while three students $(7.5 \%)$ thought that grading was very useful. For justification, the respondents cited various reasons. Highlighting the benefits, students emphasised that grades could serve as a concrete and useful point of reference in determining their own performance and level of competence, and that high grades can be 
highly motivating, giving them a sense of achievements. On the other hand, one student underlined that performance in a particular situation on a given day is always influenced by a multitude of factors, so it does not necessarily reflect the actual level of competence. Some respondents see grades as rather vague, subjective, and unreliable. Within this group, one student mentioned that grades do not take into account the whole learning process but measure only the outcome, while another student openly criticised the standard numerical grading scale (1-5), suggesting a 3-point qualitative scale. This comment implies that the meaning of grades and the summative evaluation criteria are not always clear for students. Overall, most respondents emphasised that grades should always be accompanied by qualitative feedback, providing more concrete evaluation and guidance. These findings seem to confirm recent criticisms that summative assessment in contemporary higher education is extremely problematic and disorderly, and thus grades can no longer be considered as reliable sources of information about student achievement (e.g. Knight 2002). Knight (2002) also argued that the problems surrounding summative assessment are so deeply rooted that it is difficult to change current practices without touching on philosophical issues.

The next group of questions were related to peer feedback. The first item was an open-ended question exploring students' preferences regarding peer feedback while preparing the presentation. The majority of the respondents $(n=40)$ indicated that they would like to get some general comments on the content and structure of the presentation, particularly concerning the choice of the topic (12 students), the overall logic and clarity of the ideas/argumentation (11 students), and the logic of the structure (nine students). Five students emphasised that they want the others to give constructive feedback with specific suggestions on how to improve the presentation (e.g. ideas to clarify, elaborate on, add or delete). Interestingly, five students also found it important to get peer feedback on aspects related to the delivery of the presentation, such as selfconfidence and voice, which suggests that for these students a trial, small-group presentation might be extremely helpful. Other less common (and more specific) themes emerging from the responses were peer comments on the slides (three students) and language use (three students). 
With regard to the type of peer feedback after the final presentation, responses show a clear preference for general as opposed to more detailed feedback, mostly because of time constraints and the perceived academic ability of other students. Half of the respondents favoured general oral feedback in class $(n=40)$. General feedback focuses mainly on the overall performance and not so much on specific aspects, so this finding seems to confirm previous research results pointing out that non-directive peer feedback is usually more effective (Cho \& MacArthur 2010). According to Topping (2010), peer feedback is closely linked with issues of trust and psychological safety, which can be lower if the feedback is too analytical and directive. The author emphasises that the reception of directive feedback also depends on the differences between the (perceived) level of competence of the feedback giver and receiver. If the difference is perceived to be large, the receiver of the feedback is more likely to interpret directive feedback as interfering and confining, whereas if the difference is seen as small, even specific suggestions might be accepted without evoking negative feelings (Topping 2010). This underlines the importance of training students in giving peer feedback. The most typical reason that the respondents cited for their preference for general oral feedback was that oral feedback leads to a more natural, personal and interactive discussion, from which other students can also benefit. 12 students (30\%), however, expressed preference for general written feedback from peers because they saw it as less direct and thus less hurtful, particularly if it included negative criticism. Another typical justification for favouring written feedback was that it could be re-read at home and used in the future. One respondent also highlighted that Finnish students were generally reluctant to provide negative criticism, particularly in face-to-face situations, which makes written feedback more honest, particularly if given anonymously. This is an important comment, pointing to the culturally embedded nature of assessment. It is an important feature of Evans's (2013) feedback landscape model that social interaction can also refer to situations when the other person is not physically present, which implies that written feedback can also be carried out in an interactive way. Finally, one student emphasised the crucial role of the teacher in providing the students with clear criteria in advance and explicit guidance on how to give meaningful feedback. 
With regard to specific features of the presentation that the respondents expected their peers to comment on after the presentation, the most commonly mentioned aspects were related to content (including the topic and argumentation, mentioned by 34 students), delivery ( 30 students) and the structure of the presentation (16 students), with some respondents explicitly mentioning language-related issues and the design of the slides (eight and six students respectively).

Finally, the last four questions were concerned with self-assessment. The first question used a 5 -point scale ( $1=$ useful at all...5 = very useful), on which the respondents $(n=40)$ had to rate the usefulness of the activity of watching their videotaped presentation and analyse their own performance. Attitudes towards this activity were rather mixed, and the responses were fairly evenly distributed across the scale, with the same proportion of students rating the usefulness of this activity as 3 and 4 (ten students respectively, 25\%). Similarly, the same number of students (seven respectively, 17.5\%) chose the two end points of the scale, and six students (15\%) marked the usefulness of this activity as a 2 . The respondents cited multiple reasons for the high ratings (4 or 5). For example, some of them believed that this activity would promote a deeper self-analysis and allow them to see themselves from the outside, focusing also on aspects of the performance that are less conscious, such as body language, voice and errors related to language use. According to some respondents, watching the video could also help to see themselves more objectively, instead of relying on a subjective and often false (overly positive or negative) picture of their performance. Another advantage mentioned was that a more objective selfimage could make the interpretation and acceptance of peer feedback easier. Those respondents who were more critical about the use of video recording were mostly afraid that watching themselves could be a painful, awkward and demotivating experience, in particular if something went wrong during the presentation. Another potential risk reported was that some students might become too critical of themselves and end up overanalysing their own performance. Some students were afraid that the presence of the video camera might negatively affect their performance, particularly when they have to use a foreign language. On the other hand, several students admitted that even though they had never been recorded before, they found the idea exciting. 
This openness seems to confirm the idea that new and challenging technologyenhanced assessment tasks that provide opportunities for active engagement and authentic learning can be motivating. However, as it has been pointed out in the literature, the use of technology should be complemented by dialogic teaching methods emphasising such aspects as critical thinking and teachers' cognitive presence (Hosler \& Arend 2012), the level of academic challenge, the proportion of collaborative learning, and the amount and quality of interaction between teacher and students (Evans 2013). According to James (2014), assessment practices adopting a humanistic perspective enhance student learning and engagement by emphasising autonomy, critical and independent thinking, creativity, self-reflection and collaboration. This approach advocates holistic assessment strategies, which take into account the complex nature of learning as well as the role of interpersonal relationships and affective factors, most importantly trust.

The last two items in the questionnaire were related to the activity of selfgrading. On a 5-point scale ranging from not useful at all to very useful, the respondents had to rate the activity of awarding a grade to themselves followed by a brief justification. Attitudes towards this task were mixed, with the majority of respondents (14 students, 35\%) marking this activity as a 3 in the middle of the scale. This implies that they did not have a clear opinion of this activity, or that their opinions were mixed. Eight students $(27.5 \%)$ rated this activity as a 4 , emphasising such benefits as the ability to objectively evaluate themselves and measure their performance against their own expectations, as well as the opportunity of being involved in the final evaluation. These students also mentioned that such empowerment could increase not only motivation but also their need for higher achievement, an idea highlighted also by Sendziuk (2010). A few students pointed out that this activity would allow them to focus not only on their actual performance at a particular time, but also on their overall effort and learning progress. It has been argued that self-grading can enhance students' engagement with the assessment criteria, particularly if the students are involved in the creation of the criteria (Kearney 2013). Many students, however, were sceptical about the usefulness of this activity, emphasising that self-grading can be extremely 
difficult. One student was concerned about the way the self-awarded grade would count in the final evaluation, and another respondent mentioned that some students might under- or overestimate their skills or their performance. Another typical explanation for the negative response was that awarding a grade, even if it were justified, would not necessarily help them improve. These attitudes might be linked to the general negative perceptions about summative assessment in higher education, which has shifted attention from learning to documentation and criteria compliance (Torrance 2007). Nevertheless, with the help of instructional practices that combine various formative and summative assessment methods, self-grading can have a key role in the overall assessment design. In fact, Hattie's (2009) comprehensive research concluded that self-report grades have the highest positive effect on learning. Finally, an important element of self-grading is the timing of the activity. Ideally, students are asked to do this task after reading the feedback from the teacher and/or peers although one student noted that it would also be interesting to compare the similarities and differences between the self-awarded grade and the received feedback. Fischer (2011) mentioned an interesting initial selfgrading activity (combined with self-grading after receiving other forms of feedback), in which she asked students to evaluate their work based on the time and energy invested in the whole task. She concluded that a prior selfevaluation positively affected students' achievement, and encouraged them to pay more attention to quality. On the other hand, because some students tend to overestimate the importance of time and energy invested into a task, the teacher should make it clear that in real-life situations, these kinds of input are typically not taken into account when others assess the overall quality of their performance or achievement. Along the same line, Boud and Falchikov (2006) argued that in order to enhance lifelong learning skills, students should be able to also evaluate their own work without relying too much on other people's judgements.

According to James (2014), the interactionist perspective, which is widely known among sociologists and educational theorists, seems to receive less attention in actual practice. This approach underlines the crucial role of interaction between students and teachers, which is important because students 
and teachers often hold different individual and collective views about different aspects of assessment. For instance, they can differ in their perceptions of how ability is related to academic achievement, and thus can interpret the function of grades and feedback differently (Becker, Geer \& Hughes 1995). Similarly, the messages that teachers want to convey through feedback and the ways students interpret the messages can be different (Hyland 2013). Students' perceptions can sometimes create a 'hidden curriculum', stemming from the differences between the officially declared aims and forms of assessment and the actual assessment practices (Sambell \& McDowell 1998: 392). Since the hidden curriculum is thought to have a profound influence on learning, it seems that a more open dialogue is needed between students and teachers in order to better understand each other's values, views and expectations.

\section{Conclusions}

This article set out to explore students' previous experiences and current preferences regarding feedback on individual academic presentations. The findings suggest that it is useful for teachers to adopt a learning cultures perspective (James 2014) and take into account the social nature of assessment, including the wide range of individual and contextual variables as well as the important role of interpersonal relationships and affective factors. Contemporary research has pointed out that despite the diversity of feedback practices, students often fail to engage with and benefit from feedback. This might be related to the dominance of a technical perspective in assessment, which places the main emphasis on such general principles as "fairness, transparency, efficiency, the avoidance of student appeals or litigation, reliability and validity in relation to standards, and coherence between assessment processes and learning outcomes" (James 2014: 156), and advocates analytic assessment schemes. While these principles are undoubtedly crucial, James (2014) argues that problems can arise if there is an overly heavy reliance on the codification of learning and generic, standardised assessment practices without critical reflection. Others have also pointed out that increased transparency may result in instrumentalism and criteria compliance to the detriment of learning (Torrance 2007). 
If, however, genuine learning is not the primary concern of teachers, students may not capitalise on feedback. Therefore, there is a pressing need for a better alignment between the officially declared learning objectives and the actual instructional and assessment methods. The research reported here was limited in its scope, but the findings seem to strengthen previous arguments about student feedback experiences. Namely, because students bring different experiences to the classroom and hold heterogeneous views about the nature of effective feedback, teachers should adopt assessment methods that engage students more and provide options regarding the most preferred types of feedback.

\section{References}

Amsler, S. S. \& Bolsmann, C. 2012. University ranking as social exclusion. British Journal of Sociology of Education, 33 (2), 283-301. doi:10.1080/01425692.2011.649835

Andrade, H., \& Valtcheva, A. 2009. Promoting learning and achievement through selfassessment. Theory into Practice, 48 (1), 12-19. doi:10.1080/00405840802577544

Ashford-Rowe, K., Herrington, J. \& Brown, C. 2014. Establishing the critical elements that determine authentic assessment. Assessment \& Evaluation in Higher Education, 39 (2), 205-222. doi:10.1080/02602938.2013.819566

Becker, H. S., Geer, B., \& Hughes, E. C. 1995. Making the grade: the academic side of college life. New Brunswick: Transaction Publishers. (Originally published 1968).

Biggs, J. \& Tang, C. 2011. Teaching for quality learning at university: what the student does (4th ed.). Maidenhead: McGraw-Hill/Society for Research into Higher Education/Open University Press.

Bloxham, S. \& Boyd, P. 2008. Developing effective assessment in higher education: a practical guide. Maidenhead: Open University Press.

Boud, D. 2000. Sustainable assessment: rethinking assessment for the learning society. Studies in Continuing Education, 22 (2), 151-167. doi:10.1080/713695728

Boud, D. \& Falchikov, N. 2006. Aligning assessment with long-term learning. Assessment \& Evaluation in Higher Education, 31 (4). 399-413. doi:10.1080/02602930600679050

Boud, D. \& Molloy, E. (eds.). 2013. Feedback in higher and professional education. London: Routledge. 
Boyatzis, R. E. 1998. Transforming qualitative information: thematic analysis and code development. Thousand Oaks: SAGE Publications.

Cain, S. 2012. Quiet: the power of introverts in a world that can't stop talking. New York: Crown Publishers.

Chapleo, C. 2005. Do universities have 'successful' brands? International Journal of Educational Advancement, 6 (1), 54-64. doi:10.1057/palgrave.ijea.2140233

Cho, K. \& MacArthur, C. 2010. Student revision with peer and expert reviewing. Learning and Instruction, 20 (4), 328-338. doi:10.1016/j.learninstruc.2009.08.006

Clark, I. 2012. Formative assessment: assessment is for self-regulated learning. Educational Psychology Review, 24, 205-249. doi:10.1007/s10648-011-9191-6

ENQA (European Association for Quality Assurance in Higher Education). 2009. Standards and guidelines for quality assurance in the European higher education area (3rd ed.). Retrieved from http://www.enqa.eu/wp-content/uploads/2013/06/ESG_3edition-2.pdf

Evans, C. 2013. Making sense of assessment feedback in higher education. Review of Educational Research, 83 (1), 70-120. doi:10.3102/0034654312474350

Fischer, M. 2011. A társas és önértékelés szerepe a fordítás oktatásában [The role of peerand self-assessment in translation teaching]. In J. Dróth (ed.) Szaknyelv és Szakforditás. Tanulmányok a szakforditás és a forditóképzés aktuális témáiról. Gödöllő: Szent István Egyetem GTK. 76-82.

Gardner, J., Harlen, W., Hayward, L. \& Stobart, G. 2010. Developing teacher assessment. Maidenhead: Open University Press.

Gibbs, G. 2006. Why assessment is changing. In K. Clegg \& C. Bryan (Eds.), Innovative assessment in higher education. London: Routledge. 11-22.

Hattie, J. 2009. Visible learning: a synthesis of 800+ meta-analyses on achievement. London: Routledge.

Hattie, J. \& Timperley, H. 2007. The power of feedback. Review of Educational Research, 77 (1), 81-112. doi:10.3102/003465430298487

Hosler, K. A. \& Arend, B. D. 2012. The importance of course design, feedback, and facilitation: student perceptions of the relationship between teaching presence and cognitive presence. Educational Media International, 49 (3), 217-229. doi:10.1080/09 523987.2012 .738014

Hounsell, D., McCune, V., Hounsell, J., \& Litjens, J. 2008. The quality of guidance and feedback to students. Higher Education Research and Development, 27 (1), 55-67. doi:10.1080/07294360701658765 
Hussey, T. \& Smith, P. 2002. The trouble with learning outcomes. Active Learning in Higher Education, 3 (3), 220-230. doi:10.1177/1469787402003003003

Hyland, K. 2013. Student perceptions of hidden messages in teacher written feedback. Studies in Educational Evaluation, 39 (3), 180-187. doi:10.1016/j.stueduc.2013.06.003

James, D. 2014. Investigating the curriculum through assessment practice in higher education: the value of 'learning cultures'. Higher Education, 67 (2), 155-169. doi:10.1007/s10734013-9652-6

Kearney, S. 2013. Improving engagement: the use of 'Authentic self- and peer-assessment for learning' to enhance the student learning experience. Assessment \& Evaluation in Higher Education, 38 (7), 875-891. doi:10.1080/02602938.2012.751963

Knight, P. T. 2002. Summative assessment in higher education: practices in disarray. Studies in Higher Education, 27 (3), 275-286. doi:10.1080/03075070220000662

Marginson, S. \& van der Wende, M. 2007. To rank or to be ranked: the impact of global rankings in higher education. Journal of Studies in International Education, 11 (3/4), 306-329. doi:10.1177/1028315307303544

Sambell, K. \& McDowell, L. 1998. The construction of the hidden curriculum: messages and meanings in the assessment of student learning. Assessment \& Evaluation in Higher Education, 23 (4), 391-402. doi:10.1080/0260293980230406

Sambell, K., McDowell, L. \& Montgomery, C. 2013. Assessment for learning in higher education. London: Routledge.

Sendziuk, P. 2010. Sink or swim? Improving student learning through feedback and self-assessment. International Journal of Teaching and Learning in Higher Education, 22 (3), 320-330.

Stensaker, B., Harvey, L., Huisman, J., Langfeldt, L. \& Westerheijden, D. F. 2010. The impact of the European standards and guidelines in agency evaluations. European Journal of Education, 45 (4), 577-587. doi:10.1111/j.1465-3435.2010.01450.x

Strong, B., Davis, M. \& Hawks, V. 2004. Self-grading in large general education classes: a case study. College Teaching, 52 (2), 52-57. doi:10.3200/CTCH.52.2.52-57

Topping, K. J. 2010. Methodological quandaries in studying process and outcomes in peer assessment. Learning and Instruction, 20 (4), 339-343. doi:10.1016/j. learninstruc.2009.08.003

Torrance, H. 2007. Assessment as learning? How the use of explicit learning objectives, assessment criteria and feedback in post-secondary education and training can come to dominate learning. Assessment in Education, 14 (3), 281-294. doi:10.1080/09695940701591867 
Chapter 6

Wiliam, D. 2011. What is assessment for learning? Studies in Educational Evaluation, 37 (1), 3-14. doi:10.1016/j.stueduc.2011.03.001 


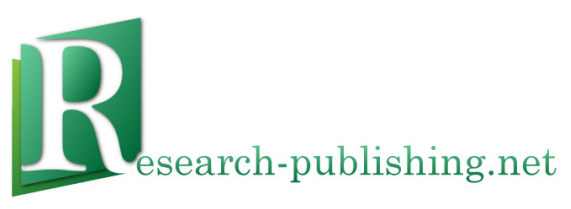

Published by Research-publishing.net, not-for-profit association Dublin, Ireland; Voillans, France, info@research-publishing.net

(C) 2015 by Research-publishing.net (collective work)

Each author retains their own copyright

Voices of pedagogical development - Expanding, enhancing and exploring higher education language learning Edited by Juha Jalkanen, Elina Jokinen, \& Peppi Taalas

Rights: All articles in this collection are published under the Attribution-NonCommercial -NoDerivatives 4.0 International (CC BY-NC-ND 4.0) licence. Under this licence, the contents are freely available online (as PDF files) for anybody to read, download, copy, and redistribute provided that the author(s), editorial team, and publisher are properly cited. Commercial use and derivative works are, however, not permitted.

\section{()ㅛ $\Theta \Theta$}

Disclaimer: Research-publishing.net does not take any responsibility for the content of the pages written by the authors of this book. The authors have recognised that the work described was not published before, or that it is not under consideration for publication elsewhere. While the information in this book are believed to be true and accurate on the date of its going to press, neither the editorial team, nor the publisher can accept any legal responsibility for any errors or omissions that may be made. The publisher makes no warranty, expressed or implied, with respect to the material contained herein. While Research-publishing.net is committed to publishing works of integrity, the words are the authors' alone.

Trademark notice: Product or corporate names may be trademarks or registered trademarks, and are used only for identification and explanation without intent to infringe.

Copyrighted material: Every effort has been made by the editorial team to trace copyright holders and to obtain their permission for the use of copyrighted material in this book. In the event of errors or omissions, please notify the publisher of any corrections that will need to be incorporated in future editions of this book.

Typeset by Research-publishing.net

Cover design by (C) Antti Myöhänen

ISBN13: 978-1-908416-25-4 (Paperback - Print on demand, black and white)

Print on demand technology is a high-quality, innovative and ecological printing method, with which the book is never 'out of stock' or 'out of print'.

ISBN13: 978-1-908416-26-1 (Ebook, PDF, colour)

ISBN13: 978-1-908416-27-8 (Ebook, EPUB, colour)

Legal deposit, Ireland: The National Library of Ireland, The Library of Trinity College, The Library of the University of Limerick, The Library of Dublin City University, The Library of NUI Cork, The Library of NUI Maynooth, The Library of University College Dublin, The Library of NUI Galway.

Legal deposit, United Kingdom: The British Library.

British Library Cataloguing-in-Publication Data.

A cataloguing record for this book is available from the British Library.

Legal deposit, France: Bibliothèque Nationale de France - Dépôt légal: septembre 2015. 